OPEN ACCESS

Edited by:

Martin Grube,

Karl-Franzens-Universität Graz,

Austria

Reviewed by:

Rebecca Case,

University of Alberta, Canada

Henrik R. Nilsson,

University of Gothenburg, Sweden

*Correspondence:

Christopher J. Barnes

c.barnes@snm.ku.dk

Specialty section:

This article was submitted to

Microbial Symbioses,

a section of the journal

Frontiers in Microbiology

Received: 18 October 2015 Accepted: 05 December 2015

Published: 25 February 2016

Citation

Barnes CJ, van der Gast CJ,

Burns CA, McNamara NP and Bending GD (2016) Temporally

Variable Geographical Distance Effects Contribute to the Assembly

of Root-Associated Fungal

Communities. Front. Microbiol. 7:195.

doi: 10.3389/fmicb.2016.00195

\section{Temporally Variable Geographical Distance Effects Contribute to the Assembly of Root-Associated Fungal Communities}

\author{
Christopher J. Barnes ${ }^{1,2 *}$, Christopher J. van der Gast ${ }^{3}$, Caitlin A. Burns ${ }^{1}$, \\ Niall P. McNamara ${ }^{4}$ and Gary D. Bending ${ }^{1}$ \\ ${ }^{1}$ School of Life Sciences, Gibbet Hill Campus, University of Warwick, Coventry, UK, ${ }^{2}$ Section of Evolutionary Genomics, \\ National History Museum of Denmark, University of Copenhagen, Copenhagen, Denmark, ${ }^{3}$ Natural Environment Research \\ Council Centre for Ecology and Hydrology, Wallingford, UK, ${ }^{4}$ Natural Environment Research Council Centre for Ecology and \\ Hydrology - Lancaster Environment Centre, Lancaster, UK
}

Root-associated fungi are key contributors to ecosystem functioning, however, the factors which determine community assembly are still relatively poorly understood. This study simultaneously quantified the roles of geographical distance, environmental heterogeneity and time in determining root-associated fungal community composition at the local scale within a short rotation coppice (SRC) willow plantation. Culture independent molecular analyses of the root-associated fungal community suggested a strong but temporally variable effect of geographical distance among fungal communities in terms of composition at the local geographical level. Whilst these distance effects were most prevalent on October communities, soil pH had an effect on structuring of the communities throughout the sampling period. Given the temporal variation in the effects of geographical distance and the environment for shaping rootassociated fungal communities, there is clearly need for a temporal component to sampling strategies in future investigations of fungal ecology.

Keywords: fungal ecology, mycorrhizal fungi, root-associated fungi, soil fungi, temporal variation in microbial communities

\section{INTRODUCTION}

Root-associated fungi are functionally and genetically diverse, and can play an integral role in connecting the aboveground biomass to the belowground ecosystem (Berendsen et al., 2012). Rootassociated fungi can be both beneficial and detrimental for plant growth. Mycorrhizal fungi are obligate root symbionts, which can dominate the root-associated microbial biomass (Högberg and Högberg, 2002) and are associated with enhanced plant nutrient uptake (Garcia et al., 2014) and disease resistance (Chakravarty and Unestam, 1987; Liu et al., 2007). Similarly, saprophytic fungi decompose organic matter, thereby promoting nutrient availability to plants (Niklaus et al., 2001). Conversely, phytopathogenic fungal species also reside within the rhizosphere, causing disease and reducing plant growth (Espinoza et al., 2008). Given the strong and variable effect the rootassociated fungal community can have on aboveground biomass, and the potential for shifts in root-associated fungal composition to influence ecosystem function (Berg and Smalla, 2009; Smith and Read, 2010), the understanding of how these communities assemble is of significant ecological importance yet remains relatively poorly understood. 
Plant hosts have been shown to play a major role in determining rhizosphere fungal communities. The main types of mycorrhizal fungal associations are generally confined to specific groups of plant (Smith and Read, 2010), and individual mycorrhizal fungal species can associate with broad or narrow ranges of plant species (Allen, 1992; Lang et al., 2010), and even genotypes within a species (Leski et al., 2010). There is also a large body of literature linking root-associated fungal community assembly with edaphic properties, with the composition of ectomycorrhizal (ECM), arbuscular mycorrhizal (AM) and nonmycorrhizal fungi all shown to be associated with specific soil parameters (Berg and Smalla, 2009). Whilst soil $\mathrm{pH}$ in particular is almost ubiquitously important for determining soil microbial community composition and function (Högberg et al., 2001; Toljander et al., 2006; Griffiths et al., 2011), soil nutrients such as $\mathrm{P}, \mathrm{K}, \mathrm{N}$, and $\mathrm{Ca}$ have also been shown to influence root-associated fungal community structure (Jones et al., 1990; Lilleskov et al., 2002; Högberg et al., 2010; Põlme et al., 2013). The high nutrient concentrations and reduced $\mathrm{pH}$ that often occur following regular fertilization within agricultural soils can have particularly profound effects on root-associated fungi, leading to reduced richness and biomass (Phillips and Fahey, 2007; Verbruggen et al., 2012; Gosling et al., 2013).

The composition of root-associated fungal communities has also been shown to vary temporally, with seasonal changes in the composition of ECM (Jumpponen et al., 2010), AM fungi (Dumbrell et al., 2011), saprophytes and pathogens (Hilton et al., 2013). However, there is much uncertainty about the factors which drive temporal changes in root-associated fungal composition, and furthermore the extent to which environment and time interact to affect community composition remains to be elucidated (Last et al., 1984; Pickles et al., 2010). Abiotic factors such as climatic variables (Swaty et al., 1998; Bahram et al., 2012), and biotic factors such as plant growth and vegetation composition vary throughout the year, and these have been hypothesized to drive changes in root-associated fungal composition over time (Dumbrell et al., 2011). However, ecological drift, in which stochastic processes contribute to heterogeneous distributions of taxa in time, could also play a role in shaping changes in root-associated communities over time (Martiny et al., 2011). A major area of uncertainty is the extent to which root-associated fungi, and microbial communities in general, show true seasonality through the formation of distinct and predictable seasonal assemblages, or simply undergo ecological drift, since comprehensive studies over long-time periods have scarcely been performed.

The way in which geographical distances between sampling locations affects root-associated community assembly has become an area of increasing interest in recent years, with the magnitude of effects varying greatly between geographical scales and systems that have been sampled. For AM fungi, strong evidence of dispersal limitation was found at the continent scale, however, this disappeared at environmental extremes (Green et al., 2004; Kivlin et al., 2011). Other studies have found limited effects of geographical distance on AM community composition at the regional level (An et al., 2008; Peay et al., 2010; van der Gast et al., 2011; Hazard et al., 2013), although spatial scaling effects at the local level may have been overlooked through 'pooling' of samples from the same sampling site. Whilst the role of distance in determining ECM communities has been studied less than AM communities, previous investigations found have found evidence of spatial scaling effects within ECM communities at the local level (Lilleskov et al., 2004), with effects also shown to be much greater at larger spatial scales, with distributions of ECM fungi reflecting barriers to dispersal at the regional and global levels (Peay et al., 2010; Bahram et al., 2012; Põlme et al., 2013). Given the repeated findings of a breakdown in community similarity within fungal communities at the regional and global spatial scales (Kivlin et al., 2011), and less frequently at the local level, the ubiquitous dispersal hypothesis (Finlay and Clarke, 1999) which proposes that microbes have a cosmopolitan distribution seem unlikely to hold true. More recently Foissner described a model of 'moderate endemicity' for protists, where some species have cosmopolitan distributions, and others are dispersal limited (Foissner, 2006, 1999), a model which could prove useful in describing the spatial distribution of other microbial communities, including root-associated fungi.

In the current study we quantified the influence of geographical distance between root-associated fungal communities and soil characteristics on structure of rootassociated fungal communities over a 13-month period. Using a commercial short rotation coppice (SRC) willow plantation in the UK, roots were collected over line transects within the site, at four time points between October 2010 and October 2011. Terminal restriction length polymorphism (TRFLP) was supplemented with 454-pyrosequencing to assess variation of fungal community composition in space and time.

\section{MATERIALS AND METHODS}

\section{Study Site and Experimental Design}

Biomass energy crops are monodominant-cropping systems that remain untilled throughout their lifetime, thus allowing microbial communities to develop over time in a relatively undisturbed soil matrix in a low-diversity aboveground system. This study used a SRC willow plantation at a field site near Lincoln, Lincolnshire, UK. The soil was a fine loam over clay, with approximately $15 \%$ clay, $49 \%$ sand, and $36 \%$ silt. The 30 year mean air temperature was $9.9^{\circ} \mathrm{C}$. Soil at the site has a $\mathrm{pH}$ gradient that ranged from 5.2 in the southern edge of the site to 6.8 in the northernmost, and has a mean total $\mathrm{C}$ and $\mathrm{N}$ content of 1.81 and $0.28 \%$ respectively. The willow was planted in 2000 at a density of 15,000 stools $\mathrm{ha}^{-1}$ and covered approximately 9.44 ha. Previously the land was rotated between wheat and oilseed rape for at least 20 years before conversion to willow. Trees were planted in paired rows, with trees within rows planted roughly $0.75 \mathrm{~m}$ apart, whilst neighboring trees between paired rows were $1.5 \mathrm{~m}$ apart. The willow consisted of 6 different varieties of Salix viminalis that were planted according to commercial practice to prevent disease spread, with Tora (60\%) being the most abundant (the others being Bjorn (10\%), Bowles Hybrid (10\%), Jorr (10\%) and Jorunn (10\%)). The crop was coppiced first in 2001, then in 2004,2007 , and 2010 with an average annual yield of $6.72 \mathrm{tha}^{-1}$. 


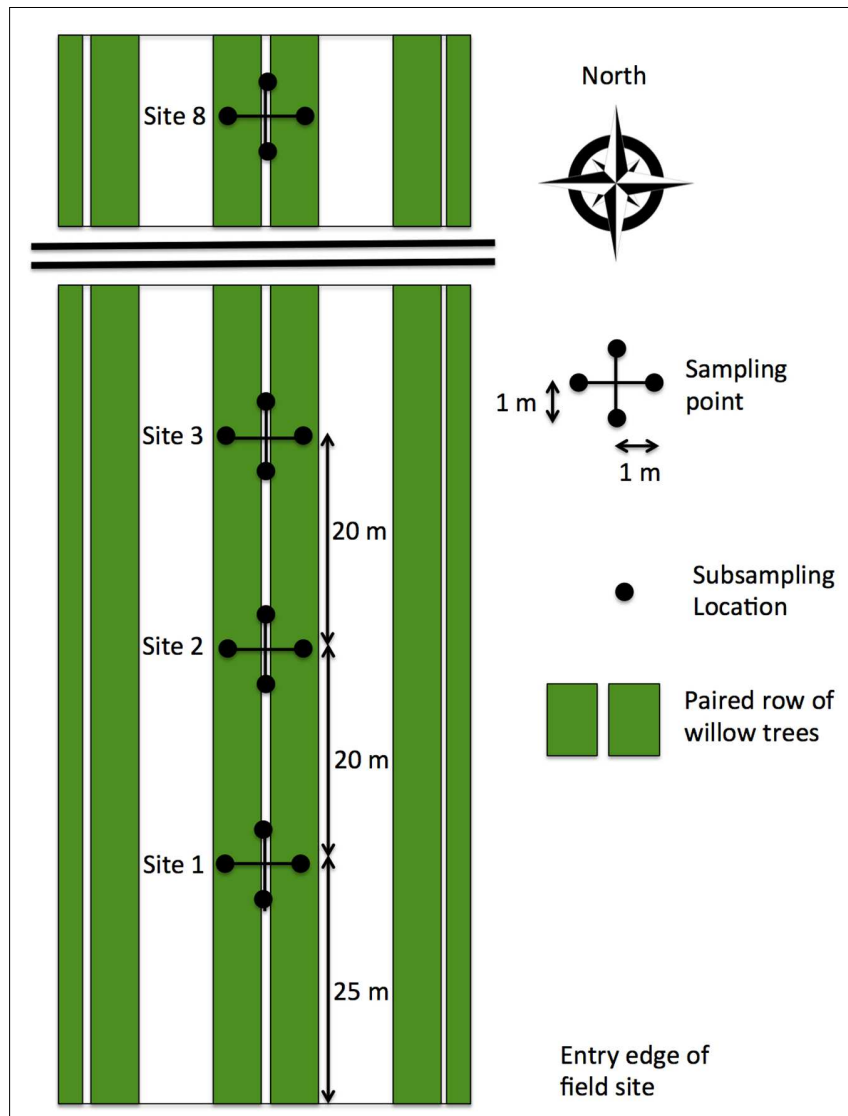

FIGURE 1 | Schematic of the line transects. Transects were sampled due north along a single paired row of the willow trees, starting $25 \mathrm{~m}$ into the site to avoid edge effects. Sampling locations were $20 \mathrm{~m}$ apart. Sampling locations consisted of $4 \mathrm{~cm} \times 15 \mathrm{~cm}$ deep soil cores taken at $1 \mathrm{~m}$ distances around the central point.

The growing season is between March and September for SRC willow in the UK. The site received concentrated PK fertilizer (Fibrophos, UK) at $660 \mathrm{~kg} \mathrm{ha}^{-1}$ at establishment, with 20 tones of compost and lime applied to the field site in February 2010. No further exogenous nutrient input was applied during the course of the experiment.

A single row of the willow was used for line transects, which started from the southern edge of the field heading north. In order to avoid edge effects, transects started $25 \mathrm{~m}$ along the row, and eight locations were sampled every $20 \mathrm{~m}$ across the row, spanning $160 \mathrm{~m}$ (Figure 1). Subsequent transects shifted sequentially $3 \mathrm{~m}$ north of the previous sampling in order to avoid repeat sampling of disturbed soil. At each location, four subsamples were taken in a cross shape $1 \mathrm{~m}$ around a central point. These consisted of $4.5 \mathrm{~cm}$ diameter soil cores that were $15 \mathrm{~cm}$ deep (van Walt, Netherlands). Transects were taken in October 2010, and July, August, and October 2011.

\section{Soil Nutrient Analysis}

For mineral analysis, $100 \mathrm{~g}$ of soil was air dried for 1 week before being ground and sieved to $<2 \mathrm{~mm}$ particle size. To measure $\mathrm{pH}, 10 \mathrm{ml}$ of soil was added to $25 \mathrm{ml}$ deionized water and the mixture shaken for $15 \mathrm{~min}$ before measurement using a $\mathrm{pH}$ meter (Accumet AB15, Fischer Scientific, UK). In order to measure available $\mathrm{P}, 5 \mathrm{~g}$ of finely ground soil was shaken for $30 \mathrm{~min}$ in $0.5 \mathrm{M} \mathrm{NaHCO}_{3}$, before analysis on an inductively coupled plasma optical emission spectrometer (ICP) (Jobin-Yvon ICP-OES, HORIBA, UK; Olsen, 1954). Available K and Mg were extracted by shaking $10 \mathrm{~g}$ of soil with $1 \mathrm{M} \mathrm{NH}_{4} \mathrm{NO}_{3}$ for $30 \mathrm{~min}$, followed by centrifugation. Concentrations of $\mathrm{K}$ and $\mathrm{Mg}$ in the supernatant were measured using ICP (Bremner and Keeney, 1965). $\mathrm{NH}_{4}$, and $\mathrm{NO}_{3}$ were extracted by shaking $20 \mathrm{~g}$ of soil with $10.5 \% \mathrm{~K}_{2} \mathrm{SO}_{4}$ for $2 \mathrm{~h}$, and following centrifugation, measured in the supernatant using a FIAstar 500 flow injection analyser system (FOSS, Denmark) (Bremner and Keeney, 1965; Henriksen and Selmer-Olsen, 1970).

\section{Sample Preparation}

Soil was softened by soaking at $19^{\circ} \mathrm{C}$ for $1 \mathrm{~h}$ in deionized water, before roots were hand extracted using forceps. Nonsenescent fine roots were selected by morphology (lighter color and branched structure with the presence of fine root tips). Roots less than $2 \mathrm{~mm}$ diameter were washed on a $6 \mathrm{~mm}$ sieve in order to remove adhering soil. Roots were then cut into $1 \mathrm{~cm}$ lengths and mixed thoroughly, before $0.5 \mathrm{~g}$ was taken for DNA extraction. Using the lysis tubes provided with the PowerSoil DNA isolation kit (MP Biomedicals, Cambridge, UK), roots were mechanically lysed in a TissueLyser (QAIGEN, UK) using three separate $30 \mathrm{~s}$ pulses at $30 \mathrm{~Hz}$, before undergoing the remainder of the extraction process exactly as per manufacturers instructions.

\section{TRFLP Protocol}

Labeled ITS1F (5-CTTGGTCATTTAGAGGAAGTAA-3)-6FAM and ITS4 (5-TCCTCCGCTTATTGATATGC-3')-TET primers were used to investigate root-associated fungal communities (Gardes and Bruns, 1993). PCR was performed using $25 \mathrm{ng}$ of DNA from each individual subsample in a total volume of $50 \mu \mathrm{l}$, which included $47 \mu$ l of Megamix (Microzone, Haywards Heath, $\mathrm{UK}), 1 \mu \mathrm{l}$ of forward and reverse primers, and $1 \mu \mathrm{l}$ of $25 \mathrm{ng} \mu \mathrm{l}^{-1}$ template DNA from samples. The program for PCR consisted of: $5 \mathrm{~min}$ at $92^{\circ} \mathrm{C}$; followed by 25 cycles of $30 \mathrm{~s}$ at $92^{\circ} \mathrm{C}, 90 \mathrm{~s}$ at $56^{\circ} \mathrm{C}$, followed by $30 \mathrm{~s}$ at $72^{\circ} \mathrm{C}$; a final extension of $5 \mathrm{~min}$ at $72^{\circ} \mathrm{C}$.

ITS amplicons from each subsample underwent digestion with Hpy8I (Fermentas, UK). $20 \mu \mathrm{l}$ reactions contained $200 \mathrm{ng}$ of DNA, 2 units of enzyme and $2 \mu \mathrm{l}$ of x10 manufacturer's buffer before reactions were equilibrated to $20 \mu \mathrm{l}$ using molecular grade water (MO BIO, Carlsbad, CA, USA) and incubated at $37^{\circ} \mathrm{C}$ overnight. Following digestion, samples were run through sephadex columns for further purification (SigmaAldrich, Germany). Four micro liter of digested and purified samples were then loaded on a capillary sequencer (ABI 3010, Applied Biosystems, UK). Samples were run with GeneScan 1200 LIZ ladder (Applied Biosystems, UK).

Genemarker v1.50 (Softgenetics, State College, PA, USA) was used to quantify the number and area of the resulting TRFLP peaks, which were exported to MS Excel (Microsoft, USA) for further analysis. Baseline noise was considered to be 50 fluorescence units, with peaks lower than this removed from the 
analysis. Samples were normalized by the conversion of peak areas (independently for the $5^{\prime}$ and $3^{\prime}$ ends) to percentage relative abundance of the total fluorescence area (Hilton et al., 2013).

\section{Barcoded Pyrosequencing}

The 4 subsamples collected in October 2010 at each sampling location were equilibrated to $25 \mathrm{ng} \mu \mathrm{l}^{-1}$ and $10 \mu \mathrm{l}$ of each was pooled to make a DNA template from each of the eight sampling locations for pyrosequencing. In order to improve comparability with the data produced via TRFLP, unlabeled ITS1F and ITS4 primers were used to generate pyrosequencing data. However, it should be noted that ITS1F and ITS4 primers show some selectivity (De Beeck et al., 2014) and produce relatively long fragments that can increase bias in community analyses (Ihrmark et al., 2012) when used in high-throughput sequencing. The initial PCR with the ITS primers was performed with MyTaq HS DNA polymerase (Bioline, USA) and consisted of: $1 \mu \mathrm{l}$ of DNA template, $2 \mathrm{mM}$ dNTPs and 10 pmol of each primer. Thermocycler conditions were $95^{\circ} \mathrm{C}$ for $5 \mathrm{~min} ; 40$ cycles of $95^{\circ} \mathrm{C}$ for $30 \mathrm{~s}, 55^{\circ} \mathrm{C}$ for $30 \mathrm{~s}, 72^{\circ} \mathrm{C}$ for $0.5 \mathrm{~min}$; and $72^{\circ} \mathrm{C}$ for $5 \mathrm{~min}$, using a Biometra TJ3000 thermocycler (Biometra, Germany). A secondary semi-nested PCR reaction was performed to add the fusion primer necessary for pyrosequencing. Fusion primers consisted of: GS FLX LR70-specific adapter A, a multiplex identifier (MID), and a new forward primer, a modified version of the universal M13 primer. The fusion primers used in the secondary reaction were: forward 5'- GTGTGAAATTGTTACGCT (10bp MID) CTTGGTCATTTAGAGGAAGTAA-3 and reverse $5^{\prime}$ TCCTCCGCTTATTGATATGC- $3^{\prime}$. The forward primer comprised of the A adapter (in italic type) for the pyrosequencing reaction, the 10-bp MID is part of Roche's extended MID set (www.454.com) and the final part is the modified M13 primer. The reverse primer consists of the fusion adapter B only. The secondary PCR was performed in a volume of $25 \mu \mathrm{l}$, and consisted of: $1 \mu \mathrm{l}$ of DNA template, $2 \mathrm{mM}$ dNTPs and $10 \mathrm{pmol}$ of each primer. Thermocycler conditions were: $94^{\circ} \mathrm{C}$ for $1 \mathrm{~min}$ $40 \mathrm{~s} ; 40$ cycles of $95^{\circ} \mathrm{C}$ for $20 \mathrm{~s}, 55^{\circ} \mathrm{C}$ for $20 \mathrm{~s}$ and $72^{\circ} \mathrm{C}$ for $20 \mathrm{~s}$; and $95^{\circ} \mathrm{C}$ for $10 \mathrm{~min}$. Sample concentrations were calculated by SYBR gold based quantitation (Shmidazu, Japan), before two plates of 20 equimolar concentrations of MID tagged samples were loaded onto a Roche 454 GS Junior pyrosequencer (454 Life Sciences/Roche Applied Biosystems, Nurley, NJ, USA) and sequenced at Micropathology Ltd (Coventry, UK). Raw sequence reads were deposited at the NCBI Sequence Read Archive under the accession number SRR1951015.

\section{Processing of Pyrosequencing Data}

Sequencing data underwent denoising with Acacia-1.52 software (Bragg et al., 2012). The software package 'Quantitative insights into microbial ecology' (QIIME v1.7.0, USA) was used to perform the majority of the remaining sample processing (Caporaso et al., 2010). OTUs were picked de novo using the UCLUST algorithm at $97 \%$ similarity and from these reads a representative sequence set was created from across all samples (Edgar, 2010). Chimeric sequences were removed using the UCHIME algorithm in de novo mode (as part of USEARCH8.0; Edgar et al., 2011).
Taxonomy was assigned at the $97 \%$ level using the 27.08 .2013 release of the ITS fungal database for QIIME, from the UNITE project, before an OTU table was created with the taxonomic assignment and relative amplicon abundance for each sample (Wang et al., 2007). An initial 28,125 sequences formed 2,138 OTUs. Samples were subsampled to the lowest sample number, 890 , before the removal of singletons, leaving approximately 592 reads per sample. In total, there were 4,738 reads spanning 320 OTUs. A second round of taxonomic assignments were performed on OTUs of greater than $1 \%$ relative abundance in which sequences underwent manual BLAST searches against the constantly updated online version of the UNITE database to increase taxonomic resolution (Table 3). Taxonomy was reassigned when sequence identity was $99 \%$ or greater and a DOI was added to improve data reproducibility.

\section{Statistical Analyses}

Relative abundance data produced via TRFLP underwent arcsine transformation in order to homogenize variation before statistical analyses were performed. To compare differences in alphadiversity, the number of TRFs [terminal restriction fragment(s)] between sampling locations and sampling time points were analyzed using repeated measures analysis of variance (ANOVA). Beta diversity was assessed by calculating distance decay-rates (DDR) across each transect as previously described (Green et al., 2004). Briefly, Bray-Curtis similarity matrices were created from the community data and Euclidean distance matrices were created from the distance between individual subsamples, using the vegdist package within R (Bray and Curtis, 1957). An exponential gradient was calculated by plotting the similarity values of the community against geographical distance, giving the distance-decay rate (using the formula $S=c D^{\mathrm{ddr}}$ ). Differences between the rates of decay between sampling points were assessed using the $t$-distribution method (Fowler et al., 1998).

For direct ordination, community data underwent arcsine transformations before undergoing canonical correspondence analysis (CCA) with integrated forward selection (Canoco v5.0, Wageningen, Netherlands; Braak and ter Šmilauer, 2002). In order to incorporate distance between sampling locations within the CCA, principle coordinates of neighbor matrices (PCNM) were calculated from grid coordinates for each subsample and the initial first PCNM was used as an explanatory variable (using the Vegan package of R). Forward interactive selection was performed to obtain significantly correlating explanatory variables, including soil properties $\left(\mathrm{pH}, \mathrm{C}, \mathrm{N}, \mathrm{NO}_{3}, \mathrm{NH}_{4}, \mathrm{Mg}\right.$, $\mathrm{P}$, and $\mathrm{K}$ ) and geographical separation (as PCNM1) against the ordination analysis of the community, whilst limiting the effects of multicolinearity (van den Wollenberg, 1977). The total variation explained in the ordination analysis as well as the variation explained by each explanatory variable was calculated during the analysis.

To investigate temporal variation in community composition, the TRFLP datasets were used to generate a single Bray-Curtis matrix. A non-metric multidimensional scaling (nMDS) analysis was performed and used to visualize community similarity between the different seasons. In order to partition and quantify the temporal variance explained by and time (in weeks after 
sampling started), the ADONIS function in the Vegan package of $\mathrm{R}$, using the combined community Bray-Curtis matrix and sampling time points as the main factor (either October 2010, July 2011, August 2011, or October 2011) was used. As this analysis is sensitive to the order explanatory variables are analyzed, individual ADONIS analyses were performed for each month (either October, July, August) and time (in weeks after sampling started) and placed in order of largest proportion of variation explained before a combined analysis was performed.

To compare community profiles produced using TRFLP and 454 pyrosequencing approaches, using the October 2010 dataset a paired $t$-test was performed between the average number of TRF at each sampling location and the number of OTU determined using pyrosequencing. In addition a DDR was calculated for the pyrosequencing dataset as described above, and this was compared to the DDR curve produced using TRFLP data, using the $t$-distribution method, as used previously.

\section{RESULTS}

\section{Edaphic Properties}

There were strong gradients in $\mathrm{pH}$, available $\mathrm{P}$ and available $\mathrm{K}$ across transects, which were conserved across all seasons (Figures 2A-C), with $\mathrm{P}(r=0.687, P<0.001)$ and $\mathrm{K}(r=0.573$, $P<0.001)$ inversely correlating with $\mathrm{pH}$. $\mathrm{pH}$ ranged from 5.2 to 6.8 across the $160 \mathrm{~m}$ transect in all seasons, while available $\mathrm{P}$ varied from $80 \mathrm{mg} \mathrm{kg}^{-1}$ to $35 \mathrm{mg} \mathrm{kg}^{-1}$ across the transect in October 2010, and from 40 to $20 \mathrm{mg} \mathrm{kg}^{-1}$ in the following seasons. Similarly available $\mathrm{K}$ was present at over $300 \mathrm{mg} \mathrm{kg}^{-1}$ in transect sites $1-3$ and at approximately $200 \mathrm{mg} \mathrm{kg}^{-1}$ in sites $5-8$ across all time points. The available $\mathrm{Mg}$ concentration did not significantly change over the length of transects or over time (Figure 2D). Both $\mathrm{NO}_{3}(P<0.001)$ and $\mathrm{NH}_{4}$ demonstrated significant $(P<0.001)$ variation over time, with highest concentrations in the October 2010 and July 2011 transects respectively (Figures $2 \mathbf{E}, \mathbf{F}$ respectively). Whilst $\mathrm{NH}_{4}$ ranged from 1.59 to $9.59 \mathrm{mg} \mathrm{kg}^{-1}$, no significant differences were found between sampling locations, $\mathrm{NO}_{3}$ ranged from 0.54 to 8.60 and significantly varied between sampling locations $(P<0.001)$.

\section{Fungal Community Analysis}

From the root-associated fungal TRFLP analysis, 273 different TRFs were identified over the four seasons, with TRF richness ranging between 22.0 and 83.8 across sampling locations. TRF richness significantly varied between sampling locations $(P=0.023)$, with site $4(60 \mathrm{~m}$ into the transect $)$ consistently having a lower TRF richness than the other sites. The number of TRFs did not differ between sampling times $(P=0.058)$.

Distance decay-rates were calculated to quantify the breakdown in community similarity of the root-associated fungi across each transect. All seasons showed some decline in similarity over transects, with the DDR varying throughout the sampling period, from $-0.136(P=0.001)$ in October 2010 , to $-0.171(P=0.001),-0.017(P=0.001)$ and $-0.115(P=0.001)$ in July 2011, August 2011 and October 2011 respectively (Figure 3). The August 2011 transect had a significantly lower rate of decay across the transect than all other sampling points $(P=0.001, P=0.001$ and $P=0.001$ for October 2010, July 2011, and October 2011 respectively), whilst none of these others were significantly different to each other (Supplementary Table S1).

\section{Investigating Distance and Edaphic Effects on the Root-Associated Fungal Community}

Canonical correspondence analyses were performed on the TRFLP data with integrated forward selection of explanatory variables (Table 1). Soil $\mathrm{pH}$ was associated with composition in every season except October 2011 (October $2010 P=0.002$, July 2011 and $P=0.002$, August $2011 P=0.01$ ), accounting for between 7.1 and $9.2 \%$ of the variation in the root-associated fungal community. The geographical separation (as PCNM1) across the transect significantly correlated with community variation in both October $2010(P=0.002)$ and October 2011 $(P=0.002)$, accounting for 4.8 and $8.4 \%$ of community variation.

\section{Investigating Temporal Changes in the Structure of the Root-Associated Fungal Community}

An initial nMDS was performed in order to visualize changes in community composition over time (Figure 4). In order to test for significance and quantify temporal changes in community variation, ADONIS analyses were performed to analyse the variance between month of sampling (July, August, and October) and time (in weeks after sampling). Both the month of sampling and time independently accounted for change within the community (Table 2), with month of sampling accounting for $7.16 \%$ of change with the root-associated fungi $(P=0.014)$ and time $1.53 \%(P=0.014)$.

\section{4-Pyrosequencing Assessment of the October 2010 Community}

The pooled DNA stocks for each of the eight sampling locations of the October 2010 transect underwent pyrosequencing to assess the diversity of root-associated fungi. All reads that could be assigned to a phylum were from the Basidiomycota and Ascomycota, with Basidiomycota the dominant fungal phylum, averaging $68.02 \%$ of reads and Ascomycota $6.90 \%$ of reads from October 2010. Basidiomycota were also more diverse than the Ascomycota, with an average of 41.75 and 9.38 OTUs respectively across the October 2010 community.

OTUs were assigned to the highest taxonomic classification and investigated further. The OTUs consisted of a few dominant and many rare OTUs, with only 15 OTUs having an average abundance greater than $1 \%$ (Table 3). Reads assigned to a Sebacinales OTU were the most abundant, accounting for $15.00 \%$ average abundance, whilst a Cortinarius diasemospermus OTU was the second most abundant accounting for a further $10.75 \%$ average community abundance. Whilst 4 of the 10 most abundant OTUs were assigned within the Cortinarius genus, a further 2 were assigned within the Sebacinales order and another 2 to the Thelephoraceae. Literature suggests 


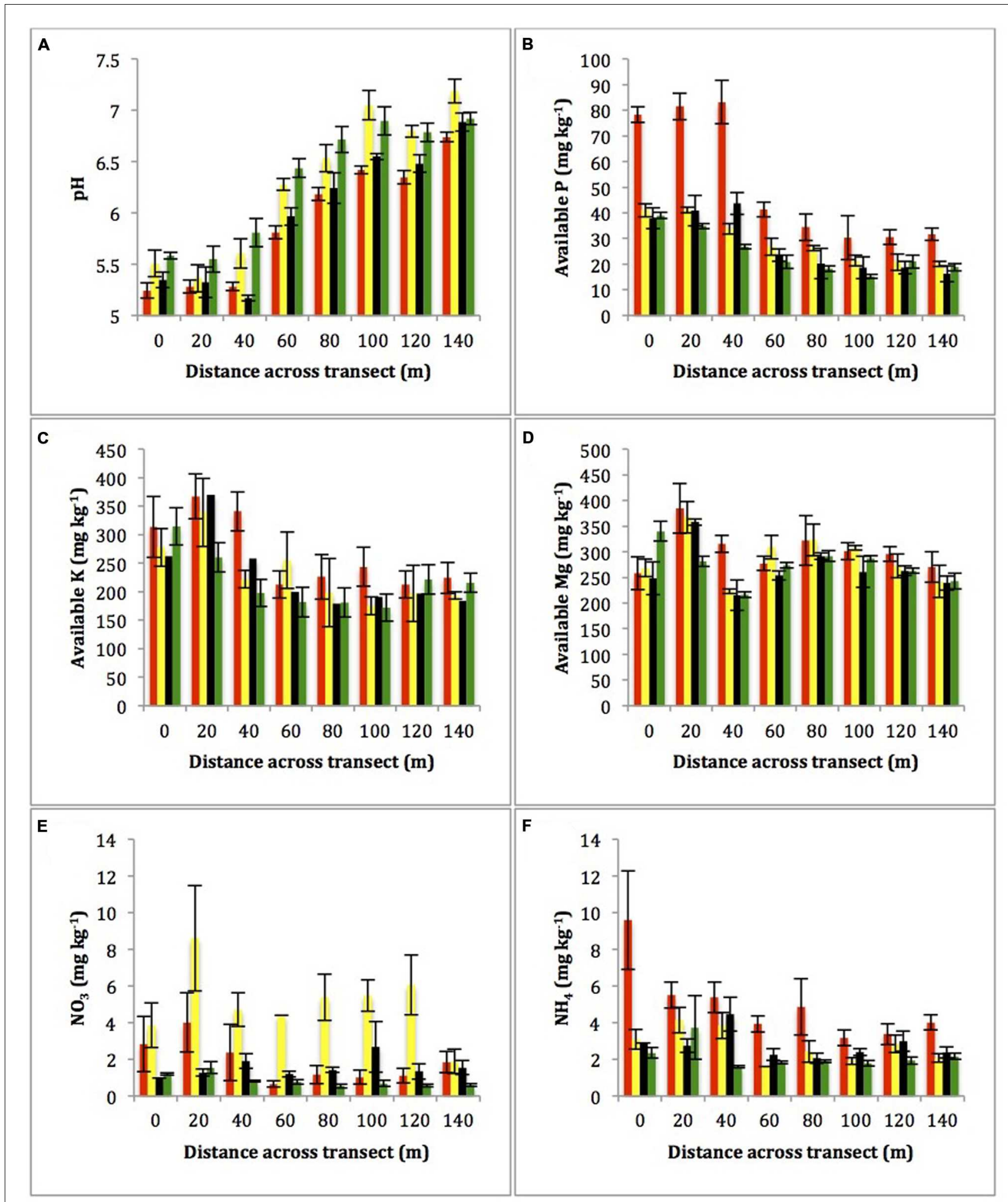

FIGURE 2 | Average of the four subsamples per sampling location of (A) pH, (B) available $\mathrm{P}\left(\mathrm{mg} \mathrm{kg}^{-1}\right)$, (C) available $\mathrm{K}\left(\mathrm{mg} \mathrm{kg}^{-1}\right)$, (D) available $\mathrm{Mg}(\mathrm{mg}$ $\left.\mathbf{k g}^{-1}\right)$, (E) $\mathrm{NO}_{3}\left(\mathbf{m g ~ k g}^{-1}\right)$, and $(\mathbf{F}) \mathbf{N H}_{4}\left(\mathbf{m g ~ k g}^{-1}\right)$ across the transects. Error bars are $\pm 1 \mathrm{SEM}$. 


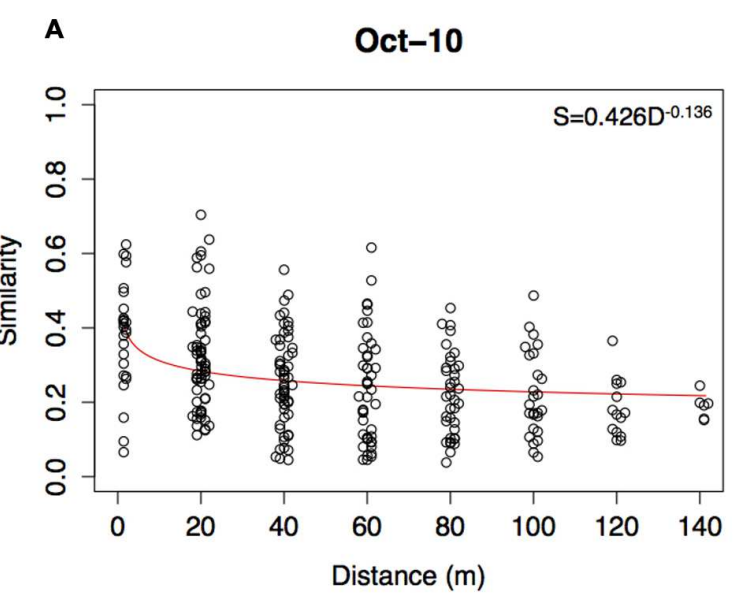

C

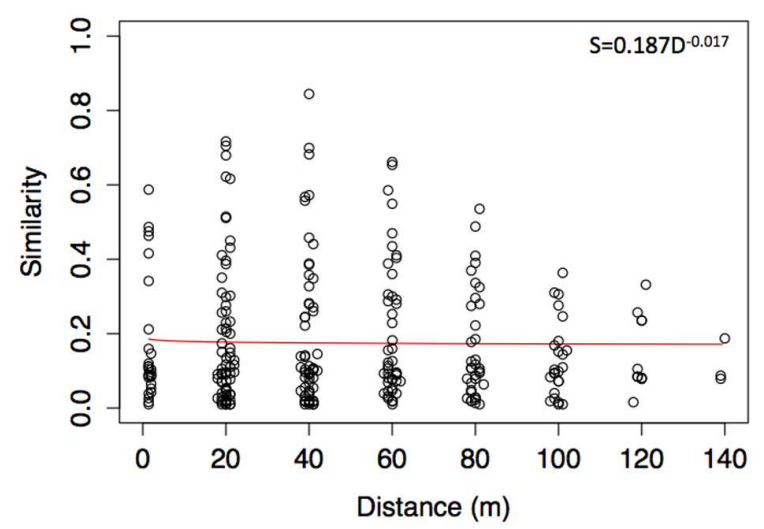

B

Jul-11

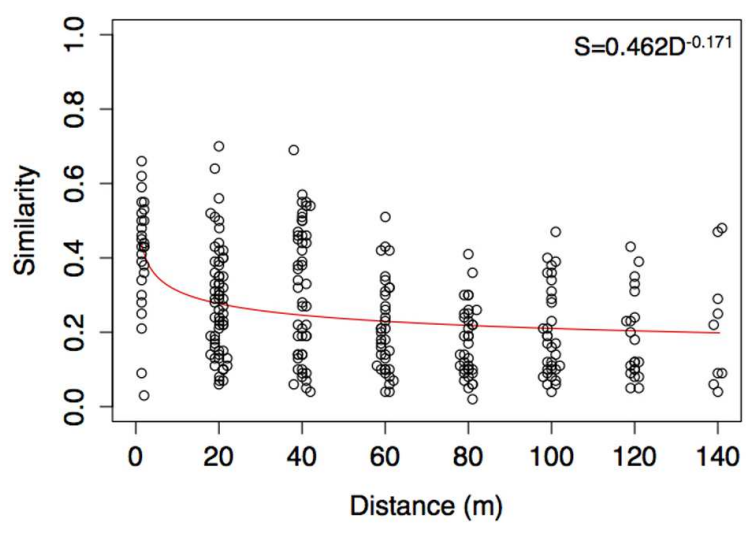

D

Oct-11

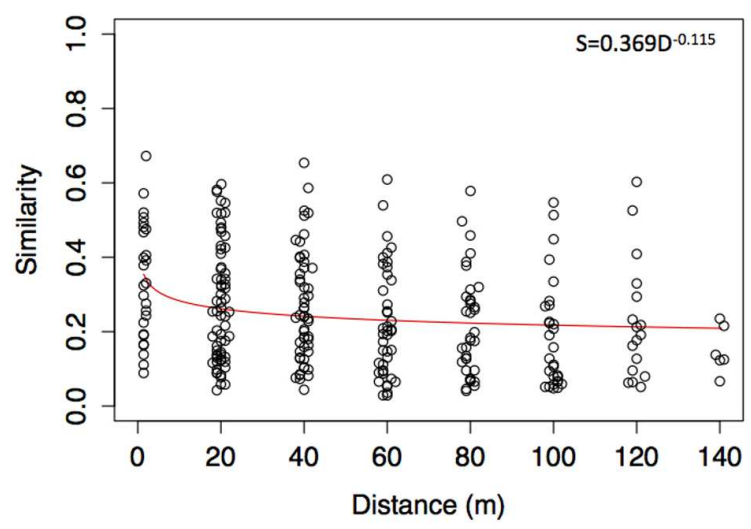

FIGURE 3 | Distance-decay of fungal community similarity over the (A) October 2010 (B) July 2011, (C) August 2011 and (D) October 2011 transects. Plotted are the Bray-Curtis similarity values against geographical distance for all paired sampling combinations, with the DDR calculated for each transect using the formula $S=c D^{\text {ddr }}$.

TABLE 1 | Canonical correspondence analysis determining the variation of the rhizosphere fungal communities from TRFLP of each transect explained by metadata parameters.

\begin{tabular}{|c|c|c|c|c|c|c|c|c|c|c|c|c|}
\hline Parameter & \multicolumn{3}{|c|}{ Oct-10 } & \multicolumn{3}{|c|}{ Jul-11 } & \multicolumn{3}{|c|}{ Aug-11 } & \multicolumn{3}{|c|}{ Oct-11 } \\
\hline $\mathrm{pH}$ & 8.5 & 2.7 & 0.002 & 9.2 & 2.7 & 0.002 & 7.1 & 1.8 & 0.01 & - & - & - \\
\hline $\begin{array}{l}\text { Distance } \\
\text { (as } \\
\text { PCNM1) }\end{array}$ & 4.8 & 1.6 & 0.004 & - & - & - & - & - & - & 8.4 & 2.6 & 0.002 \\
\hline
\end{tabular}

Abbreviations: Var. Exp. (\%), the percentage of rhizosphere fungal community variation explained by a parameter given by the canonical correspondence analysis.

that up to 10 of the 15 highly abundant OTUs could be ectomycorrhizal association forming species whilst the Thelephoraceae may also fulfill saprotrophic roles (Matheny et al., 2006; Hibbett, 2007). Reads were also assigned to other potential saprotrophs including Exophiala equina and Didymella exigua, whilst $D$. exigua may also be pathogenic along with the Seimatosporium obtusum OTU (Tanaka et al., 2011; Tedersoo et al., 2014).
There was clear evidence of spatial variation within the rootassociated fungal communities. Whilst Basidiomycota was the largest phylum within all samples, relative abundance ranged from a high of $87.1 \%$ within the community at $60 \mathrm{~m}$ across the transect, to a low of $40.1 \%$ within the site $100 \mathrm{~m}$ across (Figure 5). Ascomycota remained stable in relative abundance, ranging from 1.7 to $5.8 \%$ between sites $0-120 \mathrm{~m}$. However, the Ascomycota accounted for $25.7 \%$ of the community at $140 \mathrm{~m}$ 


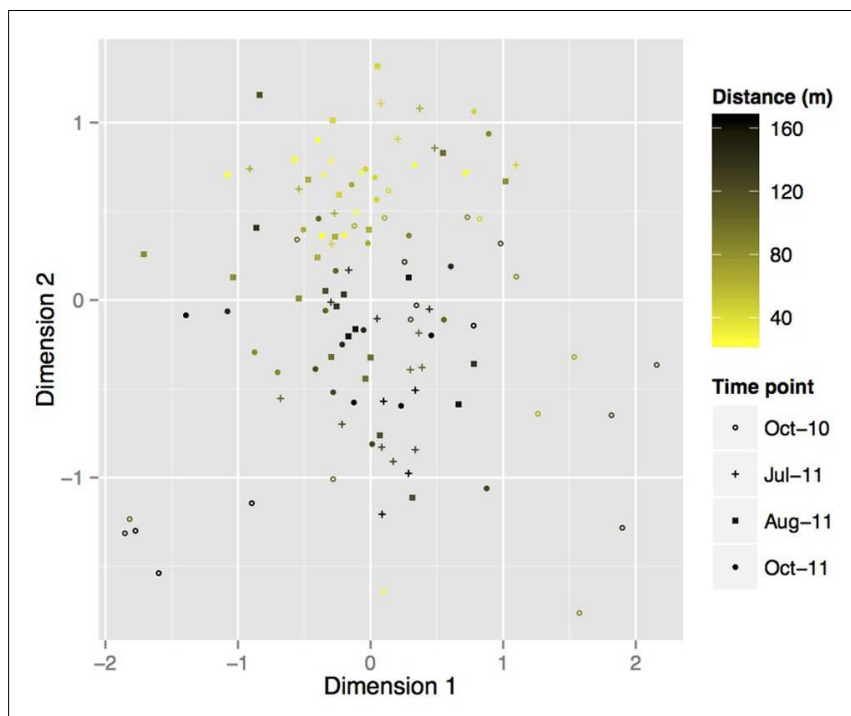

FIGURE 4 | Two-dimension nMDS plot of the TRFLP community data from all seasons combined, with each point representing a subsample. Season of origin are differentiated by marker shape whilst color illustrates the distance across the length of the transect sample originated from.

TABLE 2 | ADONIS analysis of intra-annual (seasonal) and inter-annual (time in weeks after sampling started) variation within the root-associated fungi of the SRC willow between October 2010 and October 2011.

\begin{tabular}{lcccc}
\hline Parameter & Df & $\begin{array}{c}\boldsymbol{F} \text { - } \\
\text { value }\end{array}$ & $\boldsymbol{R}^{\mathbf{2}}$ & $\begin{array}{c}\boldsymbol{P} \text { - } \\
\text { value }\end{array}$ \\
\hline $\begin{array}{l}\text { Season (as either } \\
\text { October, July, and } \\
\text { August) }\end{array}$ & 2 & 4.351 & 0.07158 & 0.014 \\
$\begin{array}{l}\text { Time (in weeks after } \\
\text { sampling commenced) }\end{array}$ & 1 & 1.8652 & 0.01534 & 0.014 \\
$\begin{array}{l}\text { Residuals } \\
\text { Total }\end{array}$ & 111 & & 0.91308 & \\
\hline & 114 & & & \\
\hline
\end{tabular}

across the transect, largely driven by a $10.8 \%$ increase in reads assigned to a putative pathogen, Seimatosporium, which was absent in nearly all other samples. OTU richness also varied across transects, with the Basidiomycota ranging from 66 OTUs at the site $40 \mathrm{~m}$ across the transect to 27 OTUs at $0 \mathrm{~m}$. Additionally, the Ascomycota ranged from just 4 OTUs at $40 \mathrm{~m}$ across the transect to 14 at $140 \mathrm{~m}$. OTU richness within the Basidiomycota strongly strongly correlated $\left(R^{2}=0.736, P=0.037\right)$ with relative abundance but the Ascomycota did not $\left(R^{2}=0.625\right.$, $P=0.097)$.

Average taxa richness produced via TRFLP for each sampling location was compared against OTU richness produced via 454pyrosequencing (Table 4). Whilst 454-pyrosequencing produced significantly greater alpha diversity estimates for each sampling location $(t=-5.161, P=0.001)$, the trend in relative fungal richness was maintained between the two techniques, with a significant correlation of $0.767(P<0.05)$. Additionally, a DDR of $-0.290(P=0.005)$ was calculated for the October 2010 rootassociated fungal community analyzed with 454-pyrosequencing, and whilst this was higher than the DDR of -0.136 produced via TRFLP, there was no significant difference between the rates produced by differing techniques $(P=0.090)$.

\section{DISCUSSION}

In this work, we show that both geographical distance and environmental variability $(\mathrm{pH})$ simultaneously affect rootassociated fungal community composition, with the magnitude of their influences being variable over time. A number of studies have found evidence for independent geographical distance effects on the composition of root-associated fungal communities (Green et al., 2004; Bahram et al., 2012; Põlme et al., 2013; Davison et al., 2015), whilst other studies have found no such effects (Tedersoo et al., 2012; Hazard et al., 2013; Mundra et al., 2015). However, here we suggest that distance effects plays a variable role in role in shaping the root-associated fungal community at the local level throughout time, whilst more temporal replicates are required to confirm if these effects are consistently greater later in the growing season within willow SRC plantations. CCAs revealed that $4.8 \%$ of community variation in October 2010 and 8.4\% in October 2011 could be explained by geographical separation. Whilst CCAs revealed that the geographical separation between samples had a significant effect on the community compositions of the October 2010 and October 2011 transects, beta-diversity was significantly higher in October 2010, July 2011, and October 2011 than August 2011. Although the gradient in $\mathrm{pH}$ and soil nutrients affected the turnover of species over transects, these properties remained stable throughout the sampling period, suggesting factors other than edaphic properties affected the spatial turnover of species. Whilst this work was performed within a managed ecosystem, these findings are in agreement with a growing number of studies performed within unmanaged systems that suggest that the ubiquitous dispersal hypothesis does not hold true for fungi (Green et al., 2004; Põlme et al., 2013; Horn et al., 2014). Interestingly, studies which have not found distance effects on root-associated fungal community composition at the local and regional level have investigated this relationship within single sampling time points, and consequently may have missed the 'window' in time that geographical separation has an effect (Hazard et al., 2013; Põlme et al., 2013).

Our results suggest that the root-associated fungal community and the parameters that regulate community assembly vary throughout the year. Whilst effects of geographical distance on community assembly were variable throughout the year, in contrast $\mathrm{pH}$ played a near ubiquitous role in affecting community composition throughout the sampling period. When the temporal variation in the root-associated fungal community was analyzed, intra-annual variation (month of sampling) rather than inter-annual variation (time in weeks after sampling started) had the largest temporal effect on the community variation, suggesting the two October sampling points shared similarity to each other, and were distinct from the July and August assemblages. Time did, however, also independently affect root-associated fungal composition, 
TABLE 3 | List of the OTUs produced with pyrosequencing of the October 2010 root associated fungal communities.

\begin{tabular}{|c|c|c|c|c|}
\hline DOI & $\begin{array}{l}\text { Accession } \\
\text { number }\end{array}$ & Taxonomic assignment & Likely habitat & $\begin{array}{c}\text { Average } \\
\text { abundance }\end{array}$ \\
\hline 10.15156/BIO/SH180002.07FU & FJ553298 & Sebacinales sp.1 & ECM & 15.00 \\
\hline 10.15156/BIO/SH188470.07FU & GU817073 & Cortinarius diasemospermus var. leptospermus & ECM & 10.75 \\
\hline 10.15156/BIO/SH180021.07FU & AJ875375 & Sebacina sp.1 & ECM & 6.04 \\
\hline 10.15156/BIO/SH186050.07FU & JF519283 & Trechisporales sp. & Unknown & 5.61 \\
\hline 10.15156/BIO/SH218870.07FU & JQ724039 & Hymenogaster griseus & ECM & 5.54 \\
\hline 10.15156/BIO/SH188476.07FU & DQ102671 & Cortinarius saniosus 1 & ECM & 4.79 \\
\hline 10.15156/BIO/SH188572.07FU & AY669621 & Cortinarius saniosus 2 & ECM & 4.33 \\
\hline 10.15156/BIO/SH188475.07FU & UDB016062 & Cortinarius parvannulatus & ECM & 3.42 \\
\hline 10.15156/BIO/SH177909.07FU & UDB008894 & Thelephoraceae sp. 1 & ECM/Saprotroph & 3.14 \\
\hline 10.15156/BIO/SH186594.07FU & GU237794 & Didymella exigua & Saprotrophic/Pathogenic & 2.48 \\
\hline 10.15156/BIO/SH197643.07FU & JF747094 & Exophiala equina & Saprotrophic & 2.11 \\
\hline 10.15156/BIO/SH180002.07FU & HQ211712 & Sebacinaceae sp. & ECM & 1.73 \\
\hline 10.15156/BIO/SH200219.07FU & JN871206 & Seimatosporium obtusum & Pathogenic & 1.38 \\
\hline 10.15156/BIO/SH181879.07FU & AF444321 & Cryptococcus podzolicus & Soil yeast & 1.13 \\
\hline 10.15156/BIO/SH189355.07FU & FJ876182 & Thelephoraceae sp. 2 & ECM/Saprotroph & 1.05 \\
\hline
\end{tabular}

For ease of reading only those that have a greater than $1.00 \%$ relative abundance are listed with their taxonomic assignment, accession numbers and DOI.

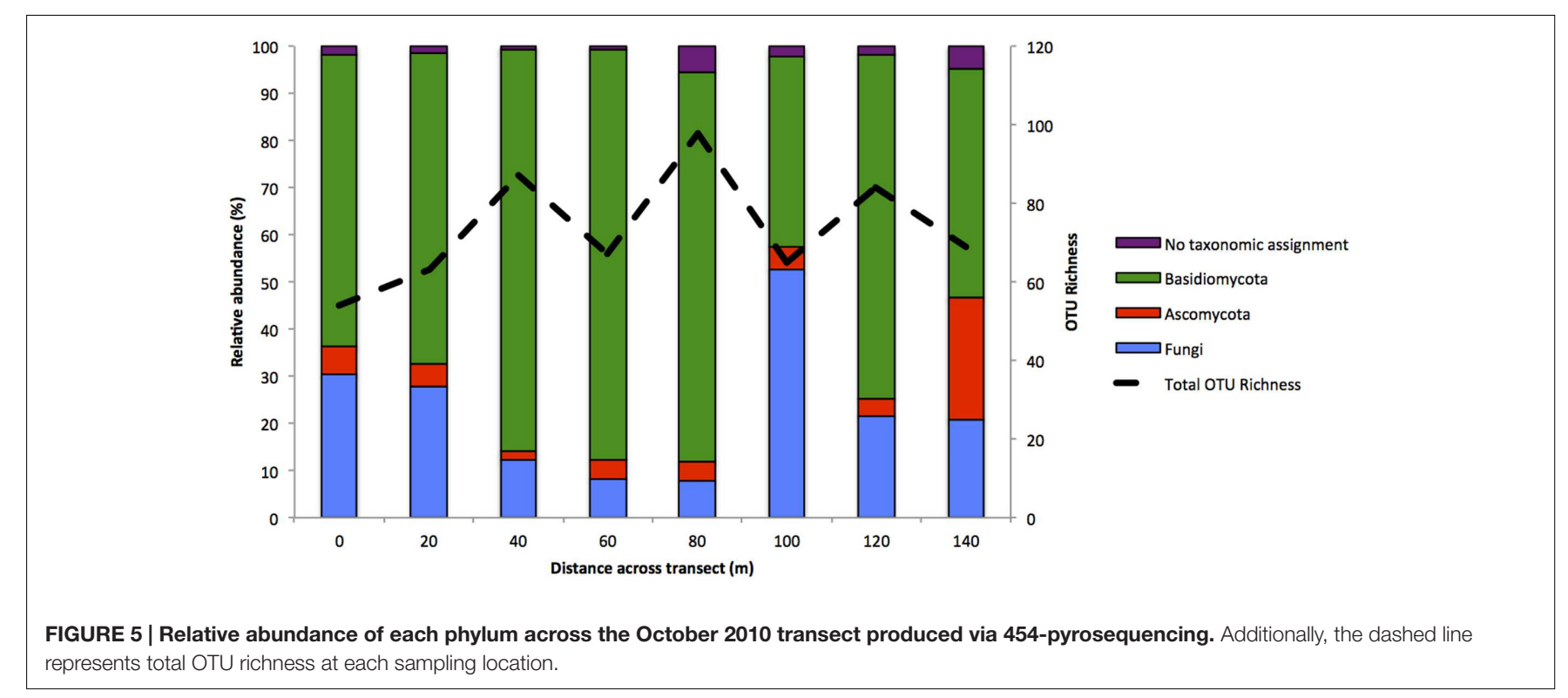

indicating that longer-term processes such as ecological drift may also be occurring. Whilst there has been a number of previous studies demonstrating seasonal community dynamics, these have mostly been performed over single growing seasons and have not enabled year-on-year comparisons, therefore have been unable to isolate seasonal effects from other more longterm temporal processes (Jumpponen et al., 2010; Dumbrell et al., 2011; Martiny et al., 2011). In this work there was only 1 yearon-year comparison, therefore results should be interpreted cautiously. However, since the communities of October 2010 and 2011 shared the most similarity, yet were still significantly different, this suggests considerable complexity in the temporal variation of root-associated fungal communities, even within a relatively simple aboveground system. Whilst community shifts have been shown between sites differing in age by multiple years (Husband et al., 2002; Fujiyoshi et al., 2011; Blaalid et al., 2012), there is a need for further studies which define the relationships among inter-annual and intra-annual variations in fungal community assembly.

As within this study, ECM communities were found to vary globally with $\mathrm{pH}$, but also with mean annual precipitation (Tedersoo et al., 2014). Changes in the composition of rootassociated fungal communities over time could reflect either a direct response to annual variation in environmental parameters (such as precipitation) or indirect effects such as changing patterns of $\mathrm{C}$ supply from the plant. For example mature Pinus sylvestris was shown to increase plant derived carbon belowground by $500 \%$ later in the growing season compared to early growing season (Högberg et al., 2010), whilst the number of fine root tips of Salix viminalis has specifically been 
TABLE 4 | Comparison of TRF richness produced via TRFLP and OTU richness produced by 454-pyrosequencing for the October 2010 root-associated fungal communities.

\begin{tabular}{lll}
\hline $\begin{array}{l}\text { Distance across } \\
\text { transect }(\mathbf{m})\end{array}$ & TRFs & 454-Pyrosequencing \\
\hline 0 & $44(5)$ & $54(8)$ \\
20 & $22(8)$ & $63(7)$ \\
40 & $68.3(2)$ & $87(2)$ \\
60 & $30.8(7)$ & $67(5)$ \\
80 & $83.3(1)$ & $98(1)$ \\
100 & $34.8(6)$ & $65(6)$ \\
120 & $46.8(4)$ & $84(3)$ \\
140 & $62(3)$ & $69(4)$ \\
\hline
\end{tabular}

Brackets indicate alpha diversity site rank from highest to lowest fungal OTU richness.

shown to increase throughout the growing season (Rytter and Hansson, 1996). Compositional shifts have also been observed in belowground microbial communities when belowground carbon allocation is increased (Phillips et al., 2002), suggesting changes in belowground plant growth dynamics throughout the year, in response to changing environmental conditions, may drive relatively short-term differences in fungal assemblages and their regulation found within this study. However, there are also a number of mechanisms that may not of been easily detected within the relatively short 13-month sampling period that may effect the root-associated fungal community. Longterm transitions in abiotic conditions, host age (Last et al., 1984; Visser, 1995; Husband et al., 2002), changing aboveground biomass composition (Blaalid et al., 2012) or even ecological succession series have been hypothesized to effect microbial assemblages over time (Deacon and Fleming, 1992; Bergemann and Miller, 2002) and there is a clear need for more studies contrasting inter and intra-annual variations within microbial communities.

454-pyrosequencing provides insightful taxonomic information about fungal composition and was used to confirm that a diverse root-associated fungal community resides within the willow monoculture. The PCR amplification with ITS1F and ITS4 primers successfully amplified a broad range of fungi and has been effectively used to detect Glomeromycota, Zygomycota, and Chytridiomycota in addition to Ascomycota and Basidiomycota within root-associated fungal communities (Yu et al., 2012), although only Ascomycota and Basidiomycota were detected within this study. These did, however, include ectomycorrhizal fungi, and a range of saprotrophs, endophytes and pathogenic fungi. Whilst many of the most abundant reads were assigned to probable ECM species, interestingly no reads were assigned to the Glomeromycota. Salix sp. can form ECM or $\mathrm{AM}$ associations depending on genotype and soil environment (Becklin et al., 2012; Corredor et al., 2012, 2014). Furthermore under some circumstances, AM inhibition by ECM fungi has been shown in laboratory experiments using willow, and this maybe replicated within willow plantations (Becklin et al., 2012).

TRFLP suffers from some well-documented limitations (Avis et al., 2006), therefore the pyrosequencing data from the
October 2010 transect was also used to provide insight into the effectiveness of TRFLP to profile fungal communities. Whilst the fungal taxa richness produced via TRFLP was significantly lower than OTU richness produced via pyrosequencing, the trend in fungal richness and DDR across sampling locations with the two technologies was well conserved. This is in agreement with other studies that suggest microbial community profiles produced between TRFLP and pyrosequencing are reproducible (Pilloni et al., 2012). Pyrosequencing too suffers a number of limitations and the subsequent bioinformatics analyses can strongly impact taxa assignment, thus there is a great need to standardize high-throughput sequencing analyses in order to improve comparability between studies using the same as well as different technologies that profile soil communities (Tedersoo et al., 2015).

Given the importance of root-associated fungi in ecosystem functioning, understanding of the factors that regulate community assembly in environmental systems remain relatively unknown. Here we suggest that the spatial scaling of root-associated fungal communities does not follow the ubiquitous dispersal model, even at the local level, and the magnitude of this spatial scaling effect varies throughout the year. Future studies of root-associated fungal community assembly should therefore not underestimate the potential of distance effects occurring at the local geographic scale, and would also benefit from multiple sampling time points to fully characterize variation within ecosystems.

\section{AUTHOR CONTRIBUTIONS}

$\mathrm{CB}$, main author of the manuscript, data producer and analysis. CvdG, assisted with statistical analyses and manuscript production. $\mathrm{CAB}$, assisted in laboratory work and bioinformatics. $\mathrm{NM}$, assisted in logistics, access to field sites and biogeochemical analyses. GB, main supervisor, obtained funding and initial experimental design.

\section{ACKNOWLEDGMENTS}

We thank Cahyo Prayogo and Lawrence Davies for assistance during sample collection and preparation. We'd also like to thank Dr. Steven Hanley (Rothamsted Research) for willow genotype analysis. This project was funded by the Natural Environment Research Council (NERC) as part of the wider Carbo-Biocrop project. For the Lincoln commercial plantation we acknowledge NERC Centre for Ecology and Hydrology National Capability funding through project NEC03487, Jon Finch and the landowner, Jonathan Wright.

\section{SUPPLEMENTARY MATERIAL}

The Supplementary Material for this article can be found online at: http://journal.frontiersin.org/article/10.3389/fmicb.2016. 00195 


\section{REFERENCES}

Allen, M. (1992). Mycorrhizal Functioning: An Integrative Plant-Fungal Process. Berlin: Springer Science \& Business Media.

An, G.-H., Miyakawa, S., Kawahara, A., Osaki, M., and Ezawa, T. (2008). Community structure of arbuscular mycorrhizal fungi associated with pioneer grass species Miscanthus sinensis in acid sulfate soils: habitat segregation along pH gradients. Soil Sci. Plant Nutr. 54, 517-528. doi: 10.1111/j.17470765.2008.00267.x

Avis, P. G., Dickie, I. A., and Mueller, G. M. (2006). A 'dirty' business: testing the limitations of terminal restriction fragment length polymorphism (TRFLP) analysis of soil fungi. Mol. Ecol. 15, 873-882. doi: 10.1111/j.1365294X.2005.02842.x

Bahram, M., Põlme, S., Kõljalg, U., Zarre, S., and Tedersoo, L. (2012). Regional and local patterns of ectomycorrhizal fungal diversity and community structure along an altitudinal gradient in the Hyrcanian forests of northern Iran. New Phytol. 193, 465-473. doi: 10.1111/j.1469-8137.2011. 03927.x

Becklin, K. M., Pallo, M. L., and Galen, C. (2012). Willows indirectly reduce arbuscular mycorrhizal fungal colonization in understorey communities. J. Ecol. 100, 343-351. doi: 10.1111/j.1365-2745.2011.01903.x

Berendsen, R. L., Pieterse, C. M. J., and Bakker, P. A. H. M. (2012). The rhizosphere microbiome and plant health. Trends Plant Sci. 17, 478-486. doi: 10.1016/j.tplants.2012.04.001

Berg, G., and Smalla, K. (2009). Plant species and soil type cooperatively shape the structure and function of microbial communities in the rhizosphere. FEMS Microbiol. Ecol. 68, 1-13. doi: 10.1111/j.1574-6941.2009. 00654.x

Bergemann, S. E., and Miller, S. L. (2002). Size, distribution, and persistence of genets in local populations of the late-stage ectomycorrhizal basidiomycete, Russula brevipes. New Phytol. 156, 313-320. doi: 10.1046/j.1469-8137.2002.00507.x

Blaalid, R., Carlsen, T., Kumar, S., Halvorsen, R., Ugland, K. I., Fontana, G., et al. (2012). Changes in the root-associated fungal communities along a primary succession gradient analysed by 454 pyrosequencing: primary succession of root-associated fungi. Mol. Ecol. 21, 1897-1908. doi: 10.1111/j.1365294X.2011.05214.x

Braak, C., and ter Šmilauer, P. (2002). "CANOCO reference manual and CanoDraw for Windows user's guide: software for canonical community ordination (version 4.5)," in Section on Permutation Methods (New York, NY: Microcomputer Power).

Bragg, L., Stone, G., Imelfort, M., Hugenholtz, P., and Tyson, G. W. (2012). Fast, accurate error-correction of amplicon pyrosequences using Acacia. Nat. Methods 9, 425-426. doi: 10.1038/nmeth.1990

Bray, J. R., and Curtis, J. T. (1957). An ordination of the upland forest communities of southern Wisconsin. Ecol. Monogr. 27, 325-349. doi: 10.2307/ 1942268

Bremner, J. M., and Keeney, D. R. (1965). Steam distillation methods for determination of ammonium, nitrate and nitrite. Anal. Chim. Acta 32, 485-495. doi: 10.1016/S0003-2670(00)88973-4

Caporaso, J. G., Kuczynski, J., Stombaugh, J., Bittinger, K., Bushman, F. D., Costello, E. K., et al. (2010). QIIME allows analysis of highthroughput community sequencing data. Nat. Methods 7, 335-336. doi: 10.1038/nmeth.f.303

Chakravarty, P., and Unestam, T. (1987). Differential influence of ectomycorrhizae on plant growth and disease resistance in Pinus sylvestris seedlings. J. Phytopathol. 120, 104-120. doi: 10.1111/j.1439-0434.1987.tb04423.x

Corredor, A. H., Rees, K. V., and Vujanovic, V. (2014). Host genotype and health status influence on the composition of the arbuscular mycorrhizal fungi in Salix bioenergy plantations. Forest Ecol. Manag. 314, 112-119. doi: 10.1016/j.foreco.2013.12.002

Corredor, A. H., Van Rees, K., and Vujanovic, V. (2012). Changes in root-associated fungal assemblages within newly established clonal biomass plantations of Salix spp. For. Ecol. Manag. 282, 105-114. doi: 10.1016/j.foreco.2012.06.045

Davison, J., Moora, M., Öpik, M., Adholeya, A., Ainsaar, L., Bâ, A., et al. (2015). Global assessment of arbuscular mycorrhizal fungus diversity reveals very low endemism. Science 349, 970-973. doi: 10.1126/science.aab1161
Deacon, K., and Fleming, L. V. (1992). "Interactions of ectomycorrhizal fungi," in Mycorrhizal Functioning: An Integrative Plant-Fungal Process, ed. M. F. Allen (London: Chapman and Hall), 249-300.

De Beeck, M. O., Lievens, B., Busschaert, P., Declerck, S., Vangronsveld, J., and Colpaert, J. V. (2014). Comparison and validation of some ITS primer pairs useful for fungal metabarcoding studies. PLoS ONE 9:e97629. doi: 10.1371/journal.pone.0097629

Dumbrell, A. J., Ashton, P. D., Aziz, N., Feng, G., Nelson, M., Dytham, C., et al. (2011). Distinct seasonal assemblages of arbuscular mycorrhizal fungi revealed by massively parallel pyrosequencing. New Phytol. 190, 794-804. doi: $10.1111 / j .1469-8137.2010 .03636 . x$

Edgar, R. C. (2010). Search and clustering orders of magnitude faster than BLAST. Bioinformatics 26, 2460-2461. doi: 10.1093/bioinformatics/btq461

Edgar, R. C., Haas, B. J., Clemente, J. C., Quince, C., and Knight, R. (2011). UCHIME improves sensitivity and speed of chimera detection. Bioinformatics 27, 2194-2200. doi: 10.1093/bioinformatics/ btr381

Espinoza, J. G., Briceño, E. X., Keith, L. M., and Latorre, B. A. (2008). Canker and twig dieback of blueberry caused by Pestalotiopsis spp. and a Truncatella sp. in Chile. Plant Dis. 92, 1407-1414. doi: 10.1094/PDIS-92-101407

Finlay, B. J., and Clarke, K. J. (1999). Ubiquitous dispersal of microbial species. Nature 400, 828-828. doi: 10.1038/23616

Foissner, W. (1999). Protist diversity: estimates of the near-imponderable. Protist 150, 363-368. doi: 10.1016/S1434-4610(99)70037-4

Foissner, W. (2006). Biogeography and dispersal of micro-organisms: a review emphasizing protists. Acta Protozool. 45, 111-136.

Fowler, J., Cohen, L., and Jarvis, P. (1998). Practical Statistics for Field Biology. Chichester: John Wiley \& Sons Ltd.

Fujiyoshi, M., Yoshitake, S., Watanabe, K., Murota, K., Tsuchiya, Y., Uchida, M., et al. (2011). Successional changes in ectomycorrhizal fungi associated with the polar willow Salix polaris in a deglaciated area in the High Arctic. Svalbard. Polar Biol. 34, 667-673. doi: 10.1007/s00300-010-0922-9

Garcia, K., Delteil, A., Conéjéro, G., Becquer, A., Plassard, C., Sentenac, H., et al. (2014). Potassium nutrition of ectomycorrhizal Pinus pinaster: overexpression of the Hebeloma cylindrosporum HcTrk1 transporter affects the translocation of both $\mathrm{K}^{+}$and phosphorus in the host plant. New Phytol. 201, 951-960. doi: $10.1111 / \mathrm{nph} .12603$

Gardes, M., and Bruns, T. D. (1993). ITS primers with enhanced specificity for basidiomycetes - application to the identification of mycorrhizae and rusts. Mol. Ecol. 2, 113-118. doi: 10.1111/j.1365-294X.1993. tb00005.x

Gosling, P., Mead, A., Proctor, M., Hammond, J. P., and Bending, G. D. (2013). Contrasting arbuscular mycorrhizal communities colonizing different host plants show a similar response to a soil phosphorus concentration gradient. New Phytol. 198, 546-556. doi: 10.1111/nph. 12169

Green, J. L., Holmes, A. J., Westoby, M., Oliver, I., Briscoe, D., Dangerfield, M., et al. (2004). Spatial scaling of microbial eukaryote diversity. Nature 432, 747-750. doi: $10.1038 /$ nature 03034

Griffiths, R. I., Thomson, B. C., James, P., Bell, T., Bailey, M., and Whiteley, A. S. (2011). The bacterial biogeography of British soils. Environ. Microbiol. 13, 1642-1654. doi: 10.1111/j.1462-2920.2011.02480.x

Hazard, C., Gosling, P., van der Gast, C. J., Mitchell, D. T., Doohan, F. M., and Bending, G. D. (2013). The role of local environment and geographical distance in determining community composition of arbuscular mycorrhizal fungi at the landscape scale. ISME J. 7, 498-508. doi: 10.1038/ismej.2012.127

Henriksen, A., and Selmer-Olsen, A. R. (1970). Automatic methods for determining nitrate and nitrite in water and soil extracts. Analyst 95, 514-518. doi: 10.1039/AN9709500514

Hibbett, D. S. (2007). After the gold rush, or before the flood? Evolutionary morphology of mushroom-forming fungi (Agaricomycetes) in the early 21st century. Mycol. Res. 111, 1001-1018. doi: 10.1016/j.mycres.2007. 01.012

Hilton, S., Bennett, A. J., Keane, G., Bending, G. D., Chandler, D., Stobart, R., et al. (2013). Impact of shortened crop rotation of oilseed rape on soil and rhizosphere microbial diversity in relation to yield decline. PLoS ONE 8:e59859. doi: 10.1371/journal.pone.0059859 
Högberg, M. N., Briones, M. J. I., Keel, S. G., Metcalfe, D. B., Campbell, C., Midwood, A. J., et al. (2010). Quantification of effects of season and nitrogen supply on tree below-ground carbon transfer to ectomycorrhizal fungi and other soil organisms in a boreal pine forest. New Phytol. 187, 485-493. doi: 10.1111/j.1469-8137.2010. 03274.x

Högberg, M. N., and Högberg, P. (2002). Extramatrical ectomycorrhizal mycelium contributes one-third of microbial biomass and produces, together with associated roots, half the dissolved organic carbon in a forest soil. New Phytol. 154, 791-795. doi: 10.1046/j.1469-8137.2002.00417.x

Högberg, P., Nordgren, A., Buchmann, N., Taylor, A. F. S., Ekblad, A., Högberg, M. N., et al. (2001). Large-scale forest girdling shows that current photosynthesis drives soil respiration. Nature 411, 789-792. doi: $10.1038 / 35081058$

Horn, S., Caruso, T., Verbruggen, E., Rillig, M. C., and Hempel, S. (2014). Arbuscular mycorrhizal fungal communities are phylogenetically clustered at small scales. ISME J. 8, 2231-2242. doi: 10.1038/ismej.2014.72

Husband, R., Herre, E. A., Turner, S. L., Gallery, R., and Young, J. P. W. (2002). Molecular diversity of arbuscular mycorrhizal fungi and patterns of host association over time and space in a tropical forest. Mol. Ecol. 11, 2669-2678. doi: 10.1046/j.1365-294X.2002.01647.x

Ihrmark, K., Bödeker, I. T. M., Cruz-Martinez, K., Friberg, H., Kubartova, A., Schenck, J., et al. (2012). New primers to amplify the fungal ITS2 region evaluation by 454 -sequencing of artificial and natural communities. FEMS Microbiol. Ecol. 82, 666-677. doi: 10.1111/j.1574-6941.2012. 01437.x

Jones, M. D., Durall, D. M., and Tinker, P. B. (1990). Phosphorus relationships and production of extrametrical hyphae by two types of willow ectomycorrhizas at different soil phosphorus levels. New Phytol. 115, 259-267. doi: 10.1111/j.14698137.1990.tb00451.x

Jumpponen, A., Jones, K. L., David Mattox, J., and Yaege, C. (2010). Massively parallel 454-sequencing of fungal communities in Quercus spp. ectomycorrhizas indicates seasonal dynamics in urban and rural sites. Mol. Ecol. 19, 41-53. doi: 10.1111/j.1365-294X.2009.04483.x

Kivlin, S. N., Hawkes, C. V., and Treseder, K. K. (2011). Global diversity and distribution of arbuscular mycorrhizal fungi. Soil Biol. Biochem. 43, 2294-2303. doi: 10.1016/j.soilbio.2011.07.012

Lang, C., Seven, J., and Polle, A. (2010). Host preferences and differential contributions of deciduous tree species shape mycorrhizal species richness in a mixed Central European forest. Mycorrhiza 21, 297-308. doi: 10.1007/s00572010-0338-y

Last, F. T., Mason, P. A., Ingleby, K., and Fleming, L. V. (1984). Succession of fruitbodies of sheathing mycorrhizal fungi associated with Betula pendula. For. Ecol. Manag. 9, 229-234. doi: 10.1016/0378-1127(84)90050-1

Leski, T., Aučina, A., Skridaila, A., Pietras, M., Riepšas, E., and Rudawska, M. (2010). Ectomycorrhizal community structure of different genotypes of Scots pine under forest nursery conditions. Mycorrhiza 20, 473-481. doi: 10.1007/s00572-010-0298-2

Lilleskov, E. A., Bruns, T. D., Horton, T. R., Taylor, D., and Grogan, P. (2004). Detection of forest stand-level spatial structure in ectomycorrhizal fungal communities. FEMS Microbiol. Ecol. 49, 319-332. doi: 10.1016/j.femsec.2004.04.004

Lilleskov, E. A., Fahey, T. J., Horton, T. R., and Lovett, G. M. (2002). Belowground ectomycorrhizal fungal community change over a nitrogen deposition gradient in Alaska. Ecology 83, 104-115. doi: 10.1890/00129658(2002)083[0104:BEFCCO]2.0.CO;2

Liu, J., Maldonado-Mendoza, I., Lopez-Meyer, M., Cheung, F., Town, C. D., and Harrison, M. J. (2007). Arbuscular mycorrhizal symbiosis is accompanied by local and systemic alterations in gene expression and an increase in disease resistance in the shoots. Plant J. 50, 529-544. doi: 10.1111/j.1365313X.2007.03069.x

Martiny, J. B. H., Eisen, J. A., Penn, K., Allison, S. D., and HornerDevine, M. C. (2011). Drivers of bacterial $\beta$-diversity depend on spatial scale. Proc. Natl. Acad. Sci. U.S.A. 108, 7850-7854. doi: 10.1073/pnas.1016 308108

Matheny, P. B., Curtis, J. M., Hofstetter, V., Aime, M. C., Moncalvo, J.-M., Ge, Z.W., et al. (2006). Major clades of Agaricales: a multilocus phylogenetic overview. Mycologia 98, 982-995. doi: 10.3852/mycologia.98.6.982
Mundra, S., Halvorsen, R., Kauserud, H., Müller, E., Vik, U., and Eidesen, P. B. (2015). Arctic fungal communities associated with roots of Bistorta vivipara do not respond to the same fine-scale edaphic gradients as the aboveground vegetation. New Phytol. 205, 1587-1597. doi: 10.1111/nph. 13216

Niklaus, P. A., Glockler, E., Siegwolf, R., and Korner, C. (2001). Carbon allocation in calcareous grassland under elevated $\mathrm{CO}_{2}$ : a combined ${ }_{13} \mathrm{C}$ pulse-labelling/soil physical fractionation study. Funct. Ecol. 15, 43-50. doi: 10.1046/j.1365-2435.2001.00485.x

Olsen, S. R. (1954). Estimation of Available Phosphorus in Soils by Extraction with Sodium Bicarbonate. Washington, DC: U.S. Department of Agriculture.

Peay, K. G., Kennedy, P. G., Davies, S. J., Tan, S., and Bruns, T. D. (2010). Potential link between plant and fungal distributions in a dipterocarp rainforest: community and phylogenetic structure of tropical ectomycorrhizal fungi across a plant and soil ecotone. New Phytol. 185, 529-542. doi: 10.1111/j.14698137.2009.03075.x

Phillips, R. L., Zak, D. R., Holmes, W. E., and White, D. C. (2002). Microbial community composition and function beneath temperate trees exposed to elevated atmospheric carbon dioxide and ozone. Oecologia 131, 236-244. doi: 10.1007/s00442-002-0868-x

Phillips, R. P., and Fahey, T. J. (2007). Fertilization effects on fineroot biomass, rhizosphere microbes and respiratory fluxes in hardwood forest soils. New Phytol. 176, 655-664. doi: 10.1111/j.1469-8137.2007.02204.x

Pickles, B. J., Genney, D. R., Potts, J. M., Lennon, J. J., Anderson, I. C., and Alexander, I. J. (2010). Spatial and temporal ecology of Scots pine ectomycorrhizas. New Phytol. 186, 755-768. doi: 10.1111/j.14698137.2010.03204.x

Pilloni, G., Granitsiotis, M. S., Engel, M., and Lueders, T. (2012). Testing the limits of 454 pyrotag sequencing: reproducibility, quantitative assessment and comparison to T-RFLP fingerprinting of aquifer microbes. PLoS ONE 7:e40467. doi: 10.1371/journal.pone.0040467

Põlme, S., Bahram, M., Yamanaka, T., Nara, K., Dai, Y. C., Grebenc, T., et al. (2013). Biogeography of ectomycorrhizal fungi associated with alders (Alnus spp.) in relation to biotic and abiotic variables at the global scale. New Phytol. 198, 1239-1249. doi: 10.1111/nph.12170

Rytter, R.-M., and Hansson, A.-C. (1996). Seasonal amount, growth and depth distribution of fine roots in an irrigated and fertilized Salix viminalis L. plantation. Biomass Bioenergy 11, 129-137. doi: 10.1016/0961-9534(96)00023-2 Smith, S. E., and Read, D. J. (2010). Mycorrhizal Symbiosis. Cambridge, MA: Academic Press.

Swaty, R. L., Gehring, C. A., Van Ert, M., Theimer, T. C., Keim, P., and Whitham, T. G. (1998). Temporal variation in temperature and rainfall differentially affects ectomycorrhizal colonization at two contrasting sites. New Phytol. 139, 733-739. doi: 10.1046/j.1469-8137.1998.00234.x

Tanaka, K., Endo, M., Hirayama, K., Okane, I., Hosoya, T., and Sato, T. (2011). Phylogeny of discosia and seimatosporium, and introduction of adisciso and immersidiscosia genera nova. Persoonia 26, 85-98. doi: 10.3767/003158511X576666

Tedersoo, L., Bahram, M., Põlme, S., Kõljalg, U., Yorou, N. S., Wijesundera, R., et al. (2014). Global diversity and geography of soil fungi. Science 346:1256688. doi: $10.1126 /$ science. 1256688

Tedersoo, L., Bahram, M., Toots, M., Diédhiou, A. G., Henkel, T. W., Kjøller, R., et al. (2012). Towards global patterns in the diversity and community structure of ectomycorrhizal fungi. Mol. Ecol. 21, 4160-4170. doi: 10.1111/j.1365294X.2012.05602.x

Tedersoo, L., Ramirez, K. S., Nilsson, R. H., Kaljuvee, A., Kõljalg, U., and Abarenkov, K. (2015). Standardizing metadata and taxonomic identification in metabarcoding studies. Giga Sci. 4:34. doi: 10.1186/s13742-0150074-5

Toljander, J. F., Eberhardt, U., Toljander, Y. K., Paul, L. R., and Taylor, A. F. S. (2006). Species composition of an ectomycorrhizal fungal community along a local nutrient gradient in a boreal forest. New Phytol. 170, 873-884. doi: 10.1111/j.1469-8137.2006.01718.x

van den Wollenberg, A. L. (1977). Redundancy analysis an alternative for canonical correlation analysis. Psychometrika 42, 207-219. doi: 10.1007/BF022 94050

van der Gast, C. J., Gosling, P., Tiwari, B., and Bending, G. D. (2011). Spatial scaling of arbuscular mycorrhizal fungal diversity is affected by farming 
practice. Environ. Microbiol. 13, 241-249. doi: 10.1111/j.1462-2920.2010. 02326.x

Verbruggen, E., Van Der Heijden, M. G., Weedon, J. T., Kowalchuk, G. A., and Röling, W. F. (2012). Community assembly, species richness and nestedness of arbuscular mycorrhizal fungi in agricultural soils. Mol. Ecol. 21, 2341-2353. doi: 10.1111/j.1365-294X.2012.05534.x

Visser, S. (1995). Ectomycorrhizal fungal succession in jack pine stands following wildfire. New Phytol. 129, 389-401. doi: 10.1111/j.1469-8137.1995.tb04309.x

Wang, Q., Garrity, G. M., Tiedje, J. M., and Cole, J. R. (2007). Naïve Bayesian classifier for rapid assignment of rRNA sequences into the new bacterial taxonomy. Appl. Environ. Microbiol. 73, 5261-5267. doi: 10.1128/AEM.00062-07

Yu, L., Nicolaisen, M., Larsen, J., and Ravnskov, S. (2012). Succession of rootassociated fungi in Pisum sativum during a plant growth cycle as examined by 454 pyrosequencing. Plant Soil 358, 225-233. doi: 10.1007/s11104-0121188-5

Conflict of Interest Statement: The authors declare that the research was conducted in the absence of any commercial or financial relationships that could be construed as a potential conflict of interest.

Copyright (c) 2016 Barnes, van der Gast, Burns, McNamara and Bending. This is an open-access article distributed under the terms of the Creative Commons Attribution License (CC BY). The use, distribution or reproduction in other forums is permitted, provided the original author(s) or licensor are credited and that the original publication in this journal is cited, in accordance with accepted academic practice. No use, distribution or reproduction is permitted which does not comply with these terms. 